\title{
Identifying the Barriers for Development of Inland Waterway Transport: a Case Study
}

\author{
Dejan Mircetic ${ }^{1, *}$, Svetlana Nikolicic ${ }^{1}$, Sanja Bojic ${ }^{1}$, and Marinko Maslaric ${ }^{1}$ \\ ${ }^{1}$ University of Novi Sad, Faculty of Technical Sciences, Trg D. Obradovica 6, 21000 Novi Sad, \\ Serbia
}

\begin{abstract}
Inland waterway transport represent environmentally friendly transport mode accompanied with other potential benefits, such as increased transport safety and increased cost savings. In order to encourage further development of inland waterway transport in this paper focus is set on the identification of the barriers that limit and prevent development of inland waterway transport. More specifically, emphasis is placed on the barriers that are preventing the cargo shifting from land to waterway transport system. Research conducted in case of Republic of Serbia investigates several barriers which are classified in four main categories: goods, logistics, infrastructure, framework conditions. Framework conditions barriers are further subdivided and classified in four subcategories: political/legal, environment, economy, technology. Results indicate that the most significant negative influence on the further development of the inland waterway transport in Serbia comes from the political/legal barriers. This result implies that the government need to pay more attention to development of inland waterway transport, as well as to make more effort to enhance the cooperation with stakeholders.
\end{abstract}

\section{Introduction}

This paper focuses on the detection of barriers which limit development of inland waterway transport. The main objective of the study is to identify key barriers for shifting cargo from land to waterway transport system. Inland waterway transport (IWT) represents economical and environmentally friendly mean of transportation of goods. In order to support increasing orientation towards intermodal transportation, European Union is encouraging the development of IWT through variety of studies and project calls. Accordingly, presented research is part of one of such project which aims at supporting the DanubeBlack Sea region to become an attractive gateway region for maritime and IWT between Central Europe and Black Sea, the Caspian region and the Far East by facilitating increased intensity and quality of cooperation between ports, regions and other key actors. The joint effort shall improve accessibility of both the ports and the region and strengthen interoperability between maritime and inland waterways as well as with their hinterland. Together with raising the awareness of the possibilities of intermodal transport, this will

* Corresponding author: dejanmircetic@gmail.com 
lead to shifting existing and attracting new cargo flows to environmentally friendly transport systems [1].

At present, aging infrastructure and inefficient, non-transparent intermodal services limit the potential of the waterway transport system. This research is built upon the belief that the cooperation of public authorities, ports and their related associations is the key success factor in order to raise quality, reliability and efficiency of the IWT system. Cooperation in itself will not yet lead to the envisaged results. Therefore in this paper a questionnaire is conducted in order to identify the main barriers that limit the development of IWT in the case study country. Case study is conducted in the Republic of Serbia, hence conclusion and results of this research are mostly limited to this country. However, results of this paper could be used for purpose of comparison with situation in some other European (landlocked) countries. There are many barriers which could be classified into different groups. For example, in research [2] authors identified 182 different administrative and regulatory barriers which obstruct the proper functioning of the European IWT industry. In our research, barriers are classified in four main categories, and framework conditions barriers are classified in four subcategories, as shown in Figure 1.

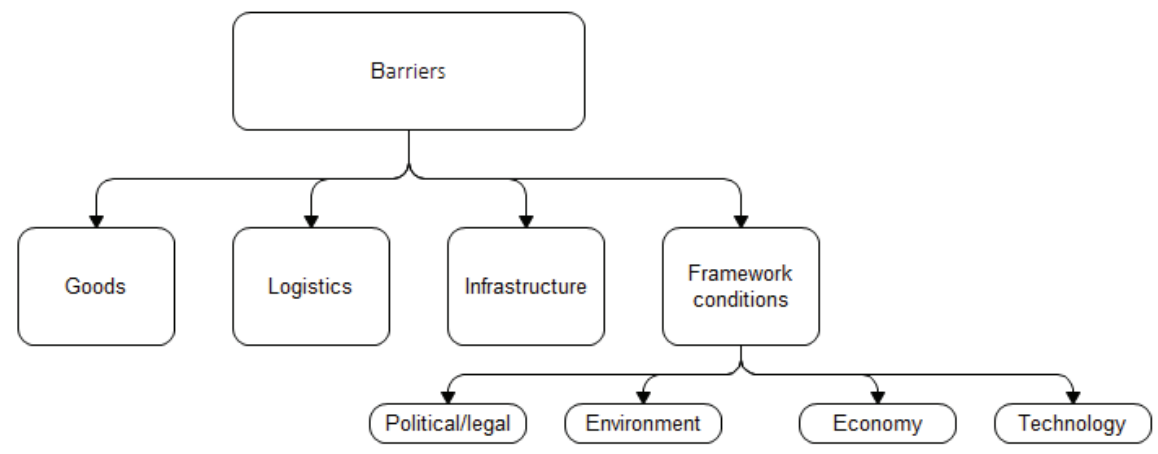

Fig. 1. Barriers for shifting the cargo from land to waterway transport. Source: authors

Beside dispersion of the barriers, in this research there is dispersion of the stakeholders which evaluate highlighted barriers. Stakeholders come from four different areas: public authority and sectoral agencies, infrastructure service providers and logistics service providers, industrial and trading companies and $\mathrm{R} \& \mathrm{D} /$ University. Dispersion of the stakeholders was necessary in order to have as much as possible comprehensive judgment of influence of different barriers from stakeholders which are practically daily encountered with them.

The remainder of this paper is organized as follows: next section gives short theoretical background and introduces the situation in the case study country regarding the IWT. In Section 3, methodology steps for questionnaire are provided. Section 4 deals with the results of the questionnaire and provides the insight about most influential barriers. Section 5 provides final remarks about influence of different barriers, and provide the concluding remarks.

\section{Theory background}

\subsection{Inland waterway transport}

Inland waterway transport could be the backbone of the future European intermodal transport chains, due to the fact that it can ship heavy as well as a large amount of commodities in combination with price advantages. Besides, IWT have still free shipment 
capacities. In Europe around $14.000 \mathrm{~km}$ of approximately $29.000 \mathrm{~km}$ of IWT are used for freight carrier. Also, Europe has around 1.500 inland ports and more than half of those are located in the main inland waterway TEN-T corridors. IWT represents the only means of land transport which does not suffer congestion problems like that of rail or road within Europe. In general, IWT are underused, but inland navigation is not considered as a truly competitive alternative to other means of land transport [3]. Estimates suggest that IWT would carry up to 425 million tons per year, including the accession countries, in the European IWT network, if the necessary action towards an integration of IWT into managed intermodal logistics chains were undertaken [4].

IWT offers a very energy efficient, reliable and safe mode of transport. It has a growth potential not yet fully explored and according to the European Commission's Transport White Paper, inland waterway by linking the European seas will have an increasing role in the freight sector [5]. However, there has been a problem of overcoming different kind of barriers for further development of IWT sector as well as problem of underinvestment in inland waterway infrastructure and suprastructure. Hence, in order to develop and implement an advanced European concept to manage intermodal transport chains with IWT as a core transport mode, we need to indentify and overcome barriers of all kinds.

\subsection{IWT in case study country}

IWT is especially important for landlocked countries, and which in the same time have navigable inland waterways. One of those countries is the Republic of Serbia, which has several navigable rivers, among which Danube is the most important one. Through the territory of the Republic of Serbia, there is a European Corridor-The Rhine-Danube Corridor, which connecting the central region around Strasbourg and Frankfurt via Southern Germany to Vienna, Bratislava, Budapest and the finally the Black Sea. Part of the Danube flowing through Serbia plays an important role in the functioning of this corridor [6]. More detailed characteristics of inland waterways in Serbia are provided in Table 1.

Table 1. The length of inland waterways in the Republic of Serbia, 2015. Source: [7]

\begin{tabular}{|c|c|c|c|c|c|}
\hline \multirow{2}{*}{} & \multicolumn{5}{|c|}{ Length of waterways (km) per ship capacity } \\
\cline { 2 - 7 } & $150 \mathrm{t}$ & $400 \mathrm{t}$ & $650 \mathrm{t}$ & $1500 \mathrm{t}$ & $3000 \mathrm{t}+$ \\
\hline Danube & 588 & 588 & 588 & 588 & 588 \\
\hline Sava & 211 & 211 & 211 & 211 & - \\
\hline Tisa & 164 & 164 & 164 & 164 & - \\
\hline Tamish & 41 & 3 & 3 & 3 & - \\
\hline Bega & 67 & 67 & 35 & 9 & - \\
\hline $\begin{array}{c}\text { Danube-Tisa- } \\
\text { Danube Canal }\end{array}$ & 522 & 505 & 449 & 13 & - \\
\hline
\end{tabular}

For the functioning of the IWT, except navigable waterway, important infrastructural complexes are inland ports as well. In the Republic of Serbia there are 8 inland ports on the Danube, 2 on the river Sava and one on the river Tisa. In the developed regions, inland ports have developed and transformed from the places of integration of river and road transportation modes, where traditionally the processes of transhipment and storage of goods were performed, into centres that combine all important logistics activities and transport, i.e. into logistics centres. Unfortunately, this does not apply to the inland ports in Serbia [6]. 


\section{Methodology}

In order to strengthen the cooperation and the commitment to work together towards the identification of the barriers, the methodology foresees the incorporation of all relevant stakeholders in the Republic of Serbia. Methodology of data/information collection was conducted through questionnaire which was carried during the regional workshop in June 2017. Questionnaire included feedback-loops and direct input to relevant topics from stakeholders. A questionnaire consisted from tree groups of question:

- general information,

- barriers for IWT use,

- opportunities for IWT use.

The first set of questions contains general information about the respondent, such as: name of organisation, type, key competence, category of stakeholders, etc. The second group of questions contains a list of barriers for development of IWT. Questions are organized according to the hierarchy from Figure 1. Minimum rating for each question was 0 , while maximum was 3 ( $3=$ most significant factor for not using the inland waterway). In the third group of questions, it is required from stakeholders to objectively assess the possibilities for massive use of inland waterways. A total of 21 questionnaires was collected. Distribution of collected questionnaires by the type of stakeholders (sector) is shown in the Table 2.

Table 2. Participation of respondents by sector. Source: authors

\begin{tabular}{|c|l|c|c|}
\hline & Sector & Number of respondents & $\mathbf{\%}$ \\
\hline 1 & Public authority and sectoral agencies & 4 & 19,05 \\
\hline 2 & Infrastructure and logistics service providers & 9 & 42,85 \\
\hline 3 & Industrial and trading companies & 4 & 19,05 \\
\hline 4 & R\&D / Universities & 4 & 19,05 \\
\hline & Total & 21 & 100,00 \\
\hline
\end{tabular}

\section{Results of analysis}

Comparative analysis of the results obtained by each sector and each group of questions is shown in the Figure 2.

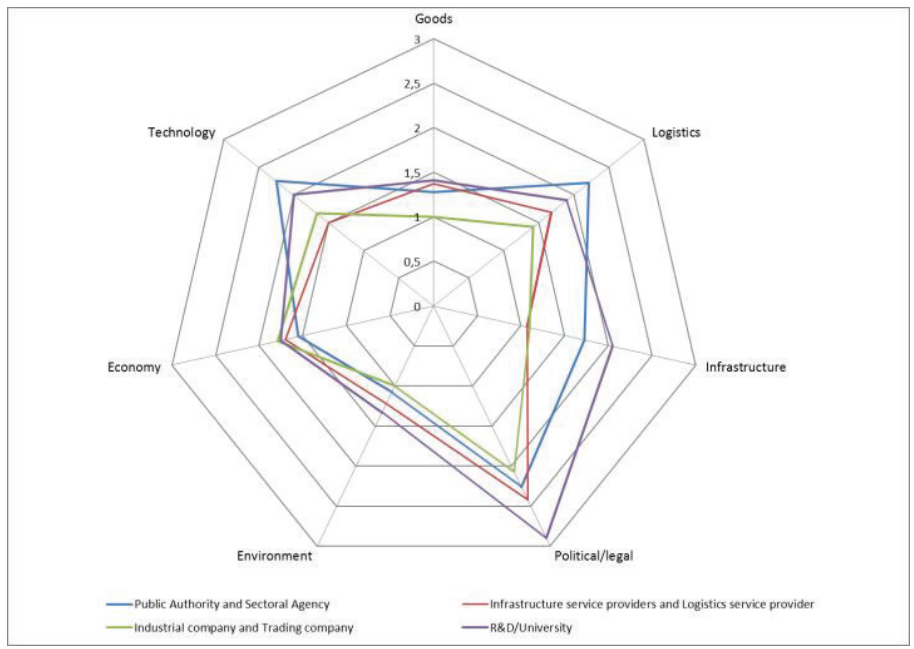

Fig. 2. The average rating for each group of questions. Source: authors 
In general the perception of the most stakeholders was that the political/legal subgroups of barriers are the most critical. However, the overall picture is not quite clear regards the type of stakeholders. A survey has shown that there is almost an even split between on the one hand the group of stakeholders having no problems and on the other hand the group of stakeholders having problems with some kind of barriers. The main difference is between group of "Public authority and sectoral agencies" and other group of stakeholders. The basic conclusions which could be made from the figure above are:

- All participants think that political/legal is the most important group of barrier for not using the inland waterway; then follow logistics and technology groups of barriers;

- Stakeholders from public authority and sectoral agencies have evaluated the technology as the most important group of barriers and as the least significant the environment;

- Infrastructure service providers and logistics service providers have evaluated the political/legal as the most important barrier and as the least significant the infrastructure;

- Industrial and trading companies have evaluated the political/legal as the most important group of barriers and as the least significant the goods and environment;

- $\mathrm{R} \& \mathrm{D} /$ University have evaluated the political/legal as the most important group of barriers and as the least significant the environment.

Since the political/legal barriers is the most influence on further development of IWT on the Danube river in the Republic of Serbia, more details about the structure of stakeholder's answers for this group of question is provided in the Figure 3.

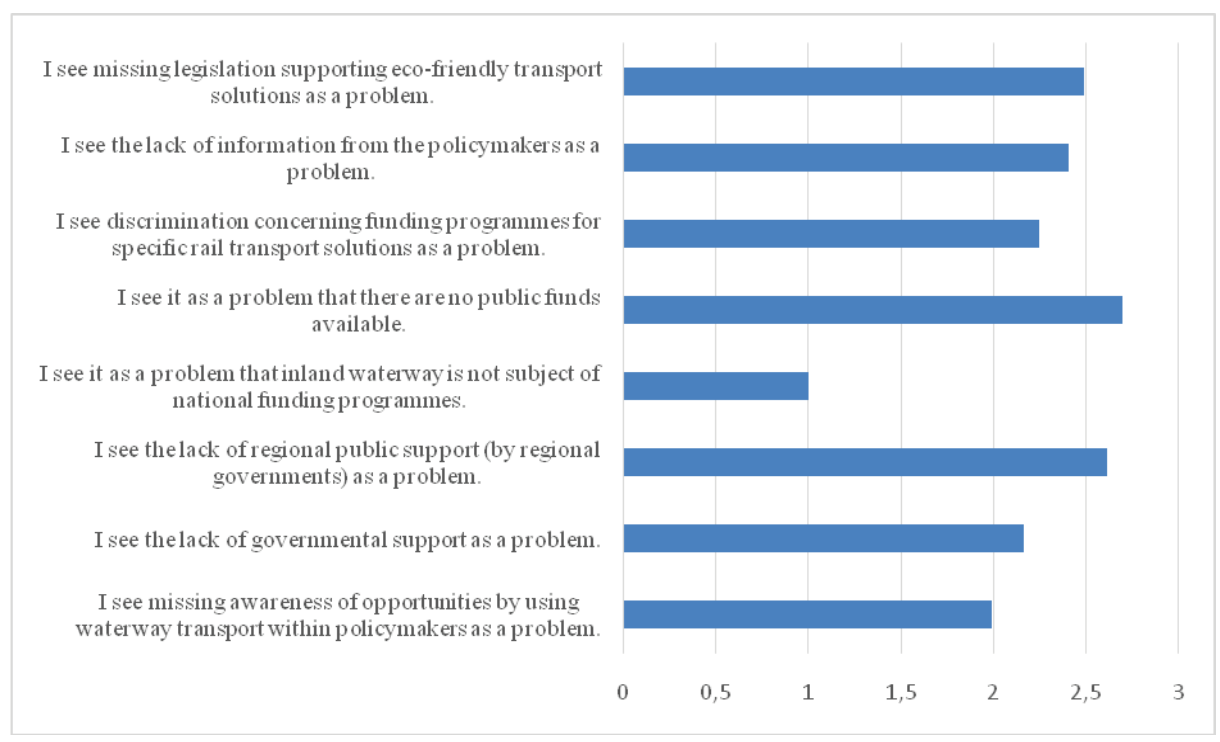

Fig. 3. Stakeholders answers regarding the influence of policy making (political/legal subgroup of questions) on the usage of IWT. Source: authors

From Figure 3, it is easy to notice that questions 4 and 6 ("I see it as a problem that there are no public funds available" and "I see the lack of regional public support (by regional governments) as a problem"), are the most influential on further development of IWT. Also questions 1 and 2, had high average rate from stakeholders, which implies that stakeholders think that government is not sufficient supporting eco-friendly solutions in transport, and that it is not providing information to the stakeholders.

Stakeholders also sugest following measures to the policy-makers, in order to improve the current situation in IWT:

- more incentives for safer, cheaper and environmentally friendly IWT transport,

- reduction of port taxes and adjustment of the regulations with the IWT users ship owners, 
- enhancing the cooperation between ports and initiatives for offering the joint transport by more shippers and container operators, in order to attract new cargo flows on IWT,

- Increasing number of incentives which are aiming on improving the quality of services and promoting IWT,

- Introducing the price list and subsisting fees by government for smaller loads.

\section{Conclusion}

Because of their efficiency and reliability IWT is considered today as one of the main mitigation option available for humanity to reduce carbon footage. However, inland waterway infrastructure, modal interaction and accommodation of wide range of goods is still poorly developed. The lack of integration and fragmentation of its infrastructure, the operational, political, and technology issues are often considered as some of the obstacles to its more intensive growth. In this paper the main barriers that exist in the Serbian IWT industry were identified. This was done by directly approaching market parties, industry organisations and public authorities, as a main group of stakeholders. The stakeholder's answers revealed that government, as the main policy maker, has the most significant negative influence on the development of the IWT in the Republic of Serbia. In the future research it will be interesting to compare results from other project member countries, in order to see is there any correlation with the presented results. A number of actions/measures that could be taken to solve or at least diminish the impact of identified problems are possible and have to be proposed in future research.

This research was supported by Danube Transnational Programme and Autonomous Province of Vojvodina, Provincial Secretariat of Finance, through project: "Regional and Transport Development in the Danube-Black Sea Region towards a Transnational Multiport Gateway Region (DBS Gateway Region)", number: DTP1-050-3.1.

This paper is supported by the research project "From horse-drawn railway to intermodal transport" within Visegrad Fund.

\section{References}

1. Interreg Danube Transnational Programme DBS Gateway Region, Available online: http://www.interreg-danube.eu/approved-projects/dbs-gateway-region (2017)

2. C. Peeters, Study on administrative and regulatory barriers in the field on inland waterway transport (2007)

3. T. Backalic, M. Maslaric, Transport Problems 7, 4, 13-24 (2012)

4. European transport policy for 2010: time to decide (White paper), (European Commission, Luxemoburg, 2001)

5. P. Mortimer, J. Ribeiro, P. Kula, S. Balik, O.A. Mistode, Transport Problems 9, Special Edition, 71-88 (2014)

6. S. Nikoličić, M. Maslarić, J. Strohmandl, D. Mirčetić, Logistics performance and transport infrastructure, Paper presented at the 3rd Logistics International Conference (Belgrade, Serbia, 2017)

7. Statistical Office of the Republic of Serbia Bilten: Saobraćaj i telekomunikacije u Republici Srbiji, 2015 (Serbia, 2017) 